\title{
Editorial
}

\section{RIESGOS PSICOSOCIALES PRESENTES EN EL TRABAJO}

En el presente volumen de Ciencia \& Trabajo tenemos el orgullo de publicar dos artículos que son fruto de investigaciones financiadas por la Fundación Científica ACHS. Estudios realizados en nuestro país, lo que nos permite extrapolar los resultados a todas las organizaciones que tengan en común el problema de investigación planteado en cada uno de ellos.

La primera de las investigaciones mencionadas estudia la exposición a factores de riesgo psicosociales presentes en el lugar de trabajo, ya que esto constituye un tema prioritario para la salud ocupacional. Específicamente se planteó el objetivo de estimar la asociación entre factores de riesgo psicosocial presentes en el trabajo y autopercepción de salud y siniestralidad laboral en conductores de vehículos de transporte de carga y pasajeros, urbanos e interurbanos, de empresas afiliadas a la Asociación Chilena de Seguridad. Destacamos esta investigación precisamente porque el día 28 de agosto del presente año en la localidad de Baquedano el conductor de un camión falleció al colisionar su vehículo contra un tren de carga; de acuerdo a los medios de comunicación, el accidente ocurrió a las

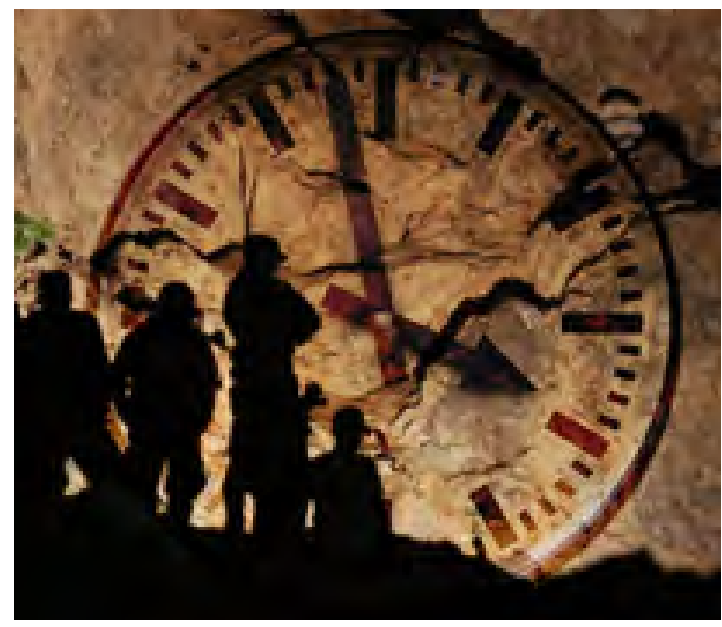

referencia, salvo "trabajo activo y desarrollo de habilidades". El 93,8\% se reportó como "sin alteraciones de salud mental". Se demostraron asociaciones estadísticamente significativas entre dimensiones del ISTAS 21 con GHQ-12 y participación en accidentes de tránsito (sólo compensaciones). De esta iniciativa nacieron intervenciones, consensuadas con las empresas, a fin de controlar/eliminar estas exposiciones para mejorar la salud y calidad de vida de los trabajadores y reducir las enfermedades profesionales y accidentes del trabajo relacionados. Esto demuestra la importancia de la colaboración entre las mutuales, su investigación, y la empresa privada.

Una segunda investigación financiada por la FUCYT-ACHS es la realizada por Alonso Carrillo, ingeniero acústico especialista en Higiene Industrial. Él estudió en terreno la transmisibilidad de asientos en grúas de horquilla y su efecto en la exposición ocupacional a vibración de cuerpo entero. Se evaluaron 4 distintos tipos de asientos de grúa horquilla, los cuales se seleccionaron por poseer distintos sistemas de amortiguamiento a las vibraciones. Adicionalmente, se evaluó la exposi4:30 horas de la madrugada, horario que es conocido como el más complejo para los seres humanos en términos de estar atentos $\mathrm{y}$ despiertos. Entre las 4 y las 6 AM es el horario en que nuestro cerebro presenta todas las condiciones para dormir: es sin duda el momento más complejo para alguien que debe realizar alguna actividad nocturna. Es por esto que quien realiza actividades de trabajo nocturno debe estar en óptimas condiciones de salud.

La investigación antes mencionada aplicó 4 cuestionarios a una muestra de 356 conductores de 4 empresas de transporte, en que $100 \%$ fue hombre con una edad promedio de 45,4 \pm 9,7 años; el $70,8 \%$ transporta pasajeros, con jornadas de 11,4 horas/día. Todas las dimensiones de ISTAS-21 resultaron con promedios inferiores a la ción a vibración del operador de la grúa de horquilla seleccionada, según el D.S. N 594/1999 y Directiva 2002/44/CE, documentos basados en la norma ISO 2631-1, con el fin de estudiar el efecto de los asientos en la exposición del operador y el nivel de riesgo asociado, para entregar recomendaciones sobre la selección y uso de asientos en grúas de horquilla.

Esta información tiene un importante valor para prevenir enfermedades producto de la vibración que genera este tipo de equipos, teniendo en cuenta que la vibración es un importante factor de riesgo para la salud, como ocurre en vehículos para el movimiento de tierras, vehículos de carga y transporte dentro y fuera de carretera, entre otros. 